\section{Protecting teeth with fruity flavours}

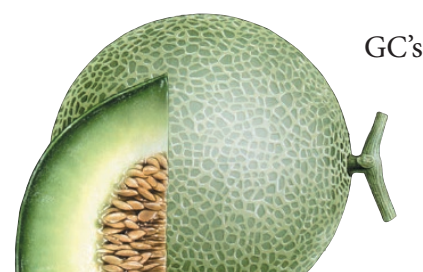

GC's Tooth Mousse is a water-based, sugarfree, topical cream containing Recaldent CPP-ACP (caesin phosphopeptide amorphous calcium phosphate). Once applied it acts like 'liquid tooth'!

It has been shown that twice daily use of a $1 \%$ CPP-ACP solution produces a $19 \%$ reduction in enamel demineralisation (Reynolds, 1988) and that the longer CPP-ACP is maintained in the mouth, the more effective the result. Consequently, GC's Tooth Mousse makes an important contribution to the protection of teeth in a wide range of situations where a mineral imbalance may arise.

Indications include restoring the mineral balance in patients with salivary deficiencies, such as xerostomia, or when proper oral hygiene procedures are difficult; and restoring the mineral content after procedures such as tooth whitening, professional cleaning, root planing and curettage, as well as reducing any resulting dentine hypersensitivity. Research has also shown that Recaldent can transform the visual opacity of new 'white spots' to a more natural 'tooth-like' translucency.

Tooth Mousse works quickly, within 2-5 minutes, and is available in five delicious flavours - strawberry, melon, vanilla, mint and tutti frutti.

For further information call GC UK Ltd on 01908218999 or visit www.gceurope.com.

\section{Have you checked your superannuation calculations?}

Read this four-point, self help guide to check you are on the right track:

1. Have you downloaded your NHS superannuation statement for the year ended 31 March 2016 from the Compass dental contact management system? If not then you should do so now.

2. Declared pensionable earnings and superannuation contributions are assumed to be correct unless you communicate with NHS Dental Services within two months of notification. Are you confident that your pensionable earnings have been correctly calculated? Many principals still believe incorrectly that pensionable earnings are $43.9 \%$ of the associate's 'gross' fees. Do you understand how your pensionable earnings have been calculated? The calculations are different for the principal if trading as a limited company.

3. Have the correct adjustments been made by principals to associates' earnings in respect of associates' under/overpayment of superannuation for the previous year? It is up to the principal to do this as otherwise large amounts can be owing from previous years.

4. Are the superannuation amounts deducted from associates' current earnings realistic? If not then a contract allocation form needs to be submitted by the principal dentist.

If you need any assistance with the above then contact Peter Howard at Booth Ainsworth LLP Chartered Accountants, Specialist Dental Accountant and NASDAL founder member.

Telephone 01614753920 or email Peter at peterh@boothainsworth. co.uk.

\section{A special offer for outstanding Class II restorations}

For dentists placing Class II restorations, Palodent V3 from Dentsply Sirona is the latest reliable sectional matrix system of choice, providing predictable and accurate contacts and a tight marginal seal with minimal flash and fast finishing.

Palodent V3 can be used with any restorative material, but is designed to best combine with SDR (Smart Dentine Replacement), the bulk fill composite base material of choice for dental professionals. Easy, quick and predictable SDR exhibits outstanding adhesion to dentine in all cavity geometries whilst remaining adaptive to hard tissue. Its flowability and self-levelling properties reduce the occurrence of voids and bubbles which lessen the possibility of post-operative sensitivity.

To finish a Class II restoration to the highest possible standards, choose ceram.x universal which brings a range of new dimensions in both anterior and posterior composite restorations. The formulation of ceram.x universal provides exceptional handling, a simplified shade matching system and fast and easy polishing, creating long-lasting restorations with excellent aesthetics.

To achieve outstanding Class II restorations Dentsply Sirona are running an exclusive offer for a limited period - Buy a Palodent V3 Introductory Kit and get an SDR refill and ceram.x universal refill of your choice, absolutely free.

To claim this offer, visit the Promotions page at dentsplyrewards.co.uk and use promo code CXV3. The offer ends on 30 September 2016.

\section{Forget string floss, use water}

Unlike string floss which recently hit the headlines due to a lack of evidence as to its effectiveness, the Waterpik Water Flosser has been clinically shown to remove plaque and reduce bleeding gums.

The first study into the Waterpik

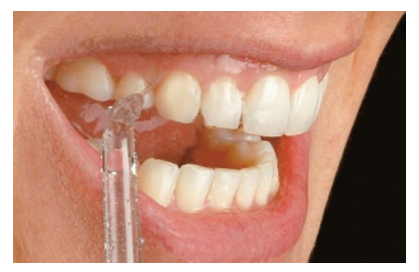

Water Flosser was conducted

at the University of Nebraska in 2004 and showed up to 52\% better improvement in gum health. To date there are a total of five clinical studies that compare the Water Flosser to string floss, consistently demonstrating that water flossing is more effective than string flossing for better oral health. Water flossing has also been shown to be up to three times as effective for removing plaque around braces and twice as effective for improving gum health around implants, compared to string floss.

Waterpik International, Inc. is a leader in innovative oral health adjuncts, offering a portfolio of Water Flossers clinically proven to benefit a wide range of patients' dental health. For more information on the science supporting its solutions and the products available, visit the website today.

For more information on Waterpik International, Inc. visit www. waterpik.co.uk. Waterpik products are available on Amazon, in Boots, Costco UK and Superdrug stores across the UK and Ireland. 